\title{
Relações pai-filho e o cuidado da criança com deficiência: olhar da equipe de saúde
}

\author{
Father-child relations and the care of children with disabilities: the health team's look \\ Relaciones padre-hijo y cuidado de niños com discapacidad: la mirada del equipo de salud
}

Recebido: 20/11/2021 | Revisado: 29/11/2021 | Aceito: 05/12/2021 | Publicado: 14/12/2021

\author{
Marcus Vinicius de Souza Dias \\ ORCID: https://orcid.org/0000-0002-8133-8390 \\ Universidade Federal de Mato Grosso do Sul, Brasil \\ E-mail: marcusvs_dias@hotmail.com \\ Fernanda Ribeiro Baptista Marques \\ ORCID: https://orcid.org/0000-0003-1024-6787 \\ Universidade Federal de Mato Grosso do Sul, Brasil \\ E-mail: fer.rbmarques@gmail.com \\ Renata Mello Barbosa de Oliveira \\ ORCID: https://orcid.org/0000-0002-9189-5895 \\ Universidade Federal de Mato Grosso do Sul, Brasil \\ E-mail: enferenata@yahoo.com.br \\ Amanda Marques Bezerra \\ ORCID: https://orcid.org/0000-0002-4834-0069 \\ Universidade Federal de Mato Grosso do Sul, Brasil \\ E-mail: amandamarquesb@outlook.com \\ Sonia Maria Oliveira de Andrade \\ ORCID: https://orcid.org/0000-0002-9897-6081 \\ Universidade Federal de Mato Grosso do Sul, Brasil \\ E-mail: soniaufms@gmail.com \\ Maria Angélica Marcheti \\ ORCID: https://orcid.org/0000-0002-1195-5465 \\ Universidade Federal de Mato Grosso do Sul, Brasil \\ E-mail: angelica.marcheti@ufms.br
}

\begin{abstract}
Resumo
Objetivo: descrever a inclusão da figura paterna no cuidado do filho com deficiência. Metodologia: trata-se de um estudo qualitativo, exploratório e descritivo. A coleta de dados se deu por meio de entrevistas, com a aplicação de questionário semiestruturado elaborado pelo pesquisador principal, direcionado aos profissionais de saúde de uma associação de reabilitação. O processo analítico se deu pela Análise de Conteúdo. Resultados: participaram nove profissionais de saúde e, após a análise minuciosa dos dados, emergiu o tema: "A inclusão do pai no cuidado do fillho com deficiência na perspectiva dos profissionais de saúde" que se compõe de quatro categorias: a figura do cuidador principal: reflexo do processo formativo; a configuração familiar como referência para o envolvimento do pai no cuidado; os papéis socioculturais das figuras materna e paterna; e a figura paterna como referência no cuidado do filho com deficiência. Considerações finais: diante das adaptações familiares frente ao evento de se ter uma criança com deficiência, a formação dos profissionais carece de conteúdos que subsidiem sua atuação para a inclusão do pai no cuidado da criança.

Palavras-chave: Relações pai-filho; Equipe de assistência ao paciente; Crianças com deficiência; Família; Cuidadores.

Abstract

Objective: to describe the inclusion of the father figure in the care of children with disabilities. Methodology: this is a qualitative, exploratory and descriptive study. Data collection were carried out by means of interviews, with a semi structured questionnaire prepared by the main researcher, aimed at health professionals from a rehabilitation association. The analytical process took place by using Content Analysis. Results: nine health professionals participated and, after a detailed analysis of the data, the theme "The inclusion of the father in the care of the disabled child from the perspective of health professionals" emerged, and is composed of four categories: the figure of the main caregiver: reflection of the training process; the family configuration as a reference for the father's involvement in care; the sociocultural roles of maternal and paternal figures; and father figure as a reference in caring for children with disabilities. Final considerations: given the family adaptations in the event of having a child with a disability, the training of professionals lacks content that supports their performance for the inclusion of the father in the child's care. Keywords: Father-child relations; Patient care team; Disabled children; Family; Caregivers.
\end{abstract}




\section{Resumen}

Objetivo: describir la inclusión de la figura paterna en el cuidado de niños con discapacidad. Metodología: se trata de un estudio cualitativo, exploratorio y descriptivo. La recogida de datos se realizó mediante entrevistas, a través de un cuestionario semiestructurado elaborado por el investigador principal, dirigido a profesionales sanitarios de una asociación de rehabilitación. El proceso analítico se llevó a cabo a través del análisis de contenido. Resultados: participaron nueve profesionales de la salud y luego de un análisis detallado de los datos surgió el tema "La inclusión del padre en el cuidado del niño discapacitado desde la perspectiva de los profesionales de la salud" y se compone de cuatro categorías: la figura del principal cuidador: reflejo del proceso de formación; la configuración familiar como referente de la implicación del padre en el cuidado; los roles socioculturales de las figuras maternas y paternas; y figura paterna como referente en el cuidado de niños con discapacidad. Consideraciones finales: dadas las adaptaciones familiares en caso de tener un hijo con discapacidad, la formación de los profesionales carece de contenidos que sustenten su desempeño para la inclusión del padre en el cuidado del niño.

Palabras clave: Relaciones padre-hijo; Grupo de atención al paciente; Niños con discapacidad; Familia; Cuidadores.
\end{abstract}

\title{
1. Introdução
}

O nascimento de uma criança com deficiência modifica a estrutura e o cotidiano familiar, e causa sobrecarga física e emocional em todos os membros (Marcheti \& Mandetta, 2016). Quando uma criança nasce com alguma deficiência, a imagem do filho perfeito é desconstruída gerando sentimentos de desilusão, desespero, tristeza e vergonha, uma vez que, para a sociedade, a deficiência, em geral, está relacionada com a limitação ou imperfeição (Vitiritti et al., 2015; Reis et al., 2017).

Os sentimentos das famílias ao se depararem com uma criança com deficiência podem ser influenciados por suas crenças e culturas. Existem famílias que buscam extrair, dessa experiência, lições valiosas que facilitam o enfrentamento da situação (Félix \& Farias, 2018).

A Lei Brasileira n ${ }^{o} 13.146$ de Inclusão da Pessoa com Deficiência, do dia 06 de julho de 2015, adotou o modelo social para conceituar a deficiência. De acordo com ela, considera-se criança com deficiência "aquela que tem impedimento de longo prazo de natureza física, mental, intelectual ou sensorial, o qual, em interação com uma ou mais barreiras, pode obstruir sua participação plena e efetiva na sociedade em igualdade de condições” com as demais crianças (Brasil, 2015).

$\mathrm{O}$ contexto da deficiência exige que a família reorganize expectativas, modifique sua estrutura para se adaptar às demandas da criança. Muitas vezes, as relações familiares tornam-se fragilizadas, pois o cuidado à criança pode exigir a presença constante de um dos membros, o que acarreta sobrecarga familiar (Andrade et al, 2018). A família busca recursos para que possa manejar as muitas demandas em saúde surgidas da condição. Reconhecer a importância da presença da família nos cuidados à criança é garantir os seus direitos e o seu papel (Marcheti \& Mandetta, 2016).

O respeito pela individualidade da criança e da família, de acordo com Marcheti e Mandetta (2016), representa um desafio contínuo aos serviços e profissionais de saúde, pois exige da equipe a inserção da família no cuidado, bem como a atenção às interações familiares, dinâmica, crenças, manejos e adaptação da família às situações emergidas .

Entretanto, os cuidados de crianças com deficiência ainda se encontram, em sua maioria, centrados na mãe e nas informações que são repassadas por ela (Félix \& Farias, 2018). Ao longo da história, verifica-se que os cuidados das crianças centram principalmente na figura materna, pois a figura do pai está vinculada ao papel de provedor e mantenedor da família. Dessa forma, a sociedade tende a não reconhecer os pais como participantes efetivos nos cuidados e no desenvolvimento de seus filhos, e os profissionais de saúde agem de modo a não envolver o pai nos cuidados à criança (Vitiritti et al., 2015).

Assuntos referentes à função paterna no cuidado são temas pouco estudados quando comparados aos da função materna. Ademais, os estudos referentes aos pais começaram a ser realizados posteriormente aos que dizem respeito às mães (Cortez et al., 2016). As demandas do mundo contemporâneo estão propiciando mudanças nas rotinas de homens e mulheres, o que afeta o desempenho de papéis sociais, dentre eles o de ser pai e mãe (Visentim \& Lhullier, 2021). 
A função paterna não é mais definida pelos parâmetros rígidos que moviam o modo de vida patriarcal, no qual o homem era a cabeça da família e único responsável pelo sustento financeiro. Observa-se um período de transição nos valores e nos modos de vida da população tanto individualmente como no contexto da família (Bernardi, 2017). O homem se adapta frequentemente para atender às demandas das relações familiares e de trabalho; porém, quando envolve o cuidado a uma criança que requer cuidados especiais de saúde, nem sempre ele é apoiado pela esposa e pela equipe de saúde que atende o filho (Andrade et al., 2018).

Os pais de filhos com deficiência têm o direito às informações e de serem incluídos nos cuidados da criança, e necessitam de ajuda e apoio para se sentirem confiantes. Assim sendo, é preciso pensar em estratégias efetivas que acolham e deem suporte aos pais de modo a garantir o seu envolvimento e participação. De um modo geral, os profissionais ainda encontram dificuldades em abordar e incluir os pais de uma criança com deficiência no processo de cuidado (Andrade et al., 2018; Visentim \& Lhullier, 2021; Bernardi, 2017). Sob esse prisma, questiona-se: Como os profissionais de saúde têm incluído a figura paterna no cuidado do filho com deficiência?

Compreende-se que a figura paterna é fundamental na vida da criança e que as ações dos profissionais de saúde, no contexto do atendimento à criança com deficiência, devem incluir o pai em sua abordagem e, assim, favorecer o vínculo, o relacionamento e o cuidado parental. Este estudo buscou, portanto, compreender a inclusão da figura paterna no cuidado do filho com deficiência na perspectiva dos profissionais de saúde.

\section{Metodologia}

Trata-se de um estudo descritivo, exploratório, com abordagem qualitativa, e que possibilita a investigação de grupos e segmentos delimitados e focalizados de histórias sociais e das relações. Essa abordagem tem fundamento teórico e permite compreender processos sociais ainda pouco conhecidos referentes a grupos particulares, proporcionando a construção de novos conceitos e categorias durante a investigação (Minayo, 2014).

O presente estudo segue o recomendado pela Resolução 466/2012 do Conselho Nacional de Saúde e foi aprovado pelo Comitê de Ética em Pesquisa da Universidade Federal de Mato Grosso do Sul com o parecer nº 2.252.518.

Para preservar a identidade dos participantes, as entrevistas foram identificadas com a letra "E" seguida do numeral de sequência das entrevistas, ex: E1.

Para manter o rigor metodológico do estudo, foi utilizado como roteiro e apoio para a construção do material produzido o Consolidated Criteria for Reporting Qualitative Research (COREQ), de autoria de Tong et al. (2007).

As entrevistas foram conduzidas pelo primeiro pesquisador, para as quais utilizou-se um roteiro semiestruturado elaborado pelos autores do estudo, composto por dados de caracterização dos profissionais e questões condutoras da narrativa do profissional quanto à participação e inclusão da figura paterna nos cuidados e tratamento do filho.

O estudo foi desenvolvido em uma associação civil e filantrópica, de caráter educacional, cultural, de assistência social e saúde, direcionada para a reabilitação de crianças e adolescentes com deficiência, localizada no estado de Mato Grosso do Sul.

Foram incluídos nesta pesquisa os profissionais que compõem a equipe de saúde e atuam diretamente na assistência às crianças e adolescentes com deficiência e seus familiares, presentes na associação no período da coleta de dados. Excluíram-se profissionais que estavam em afastamento de suas atividades no período de coleta.

Os dados foram coletados nos meses de outubro e novembro do ano de 2017, em uma sala privativa fornecida pela instituição. As entrevistas foram realizadas individualmente. A coleta de dados foi encerrada com base na pré-análise e interpretação subjetiva dos dados conforme Braun e Clarke (2019). 
As narrativas dos participantes do estudo foram gravadas em mídia digital e as entrevistas tiveram em média 30 minutos, sendo, em seguida, transcritas na íntegra pelo primeiro pesquisador.

A análise do estudo foi realizada pelos autores do estudo e se deu por meio de leitura minuciosa, exaustiva e exploratória do material selecionado de modo a extrair a reflexão compreensiva e crítica da realidade estudada. Os dados foram analisados por meio da proposta de Morse e Field (2008) de Análise Qualitativa de Conteúdo, perpassando pelos quatro processos-chave: compreender, sintetizar, teorizar e recontextualizar de modo sequencial, agrupando os achados a fim de possibilitar a teorização dos dados.

\section{Resultados}

Foram entrevistados nove profissionais, os quais fazem parte da equipe multiprofissional de saúde, ou seja: três fisioterapeutas, um psicólogo, um terapeuta ocupacional, dois enfermeiros e dois fonoaudiólogos, com tempo de formação entre nove meses e 34 anos, cinco deles com pós-graduação (lato sensu). O tempo médio de serviço dos profissionais na instituição é de, aproximadamente, 11 anos. A idade dos profissionais variou de 23 a 56 anos, sendo oito do sexo feminino e um do sexo masculino.

Após o diálogo entre a análise dos dados, o objetivo, as questões e pressupostos do estudo, emergiu o tema: "A inclusão do pai no cuidado do filho com deficiência na perspectiva dos profissionais de saúde", que exprime a compreensão, por parte dos profissionais, da inclusão da figura paterna no cuidado ao filho com deficiência e dos fatores que influenciam seu envolvimento nos cuidados. Esse tema foi composto por quatro categorias: a figura do cuidador principal: reflexo do processo formativo; a configuração familiar como referência para o envolvimento do pai no cuidado; os papéis socioculturais das figuras materna e paterna; e a figura paterna como referência no cuidado do filho com deficiência.

\subsection{A figura do cuidador principal: reflexo do processo formativo}

Essa categoria retrata o conhecimento do profissional sobre a participação da família e do pai no cuidado do filho com deficiência, e o seu processo de formação que direciona a abordagem para o cuidador principal, o que favorece a não inclusão do pai no atendimento.

Os profissionais abordam o cuidador principal que comparece à instituição com a criança para direcionar suas orientações e fornecer informações. Normalmente quem comparece como acompanhante no primeiro atendimento é a mãe ou a avó (figuras femininas). Para eles, a própria família já estabeleceu o cuidador principal em sua dinâmica familiar. Essa pessoa é a que cuida habitualmente da criança em casa ou a que não trabalha, ou ainda a que deixou de trabalhar para se dedicar aos cuidados.

Para os profissionais, a abordagem ao pai e ao sistema familiar é muito complexa e exige conhecimentos que eles consideram não possuir.

Na primeira entrevista os pacientes já vêm com uma pessoa. Daí, mesmo sem querer, fica essa pessoa que vêm no primeiro atendimento, que muitas vezes é a mãe. (E9)

É a dinâmica familiar, geralmente quem não trabalha. Geralmente tem sempre um que acaba deixando de trabalhar para cuidar da pessoa com deficiência, então abrindo mão de tudo para cuidar da pessoa. E daí, eu acabo elegendo essa pessoa para prestar os cuidados. (E3) 
Os profissionais relatam que, durante a graduação, o tema família foi abordado em um contexto geral, e não se lembram de experiências ou assuntos que tratassem da paternagem ou da figura paterna e nem do papel do pai de maneira específica.

Não fui preparada para trabalhar com figura paterna, não. Não fui não. (E8)

Que eu me lembro, especificamente, sobre figura paterna não. (E2)

Disciplina só saúde do homem, mas que não foca na figura paterna, só na parte da saúde mesmo, agora especificamente da figura paterna não, nem da família. Não! (E6)

Os profissionais do estudo acreditam que a família precisa se envolver no cuidado do filho com deficiência de forma integral e em conjunto, e reconhecem a importância da figura e do papel do pai nos cuidados da criança e na divisão de tarefas. No entanto identificam que os pais geralmente não comparecem aos atendimentos do filho.

[...] ]é em um exercício ou em uma estimulação que toda família precisa estar envolvida. É importante que todo mundo participe. (E5)

Então, fica difícil incluir a figura paterna se não vem nos atendimentos [...] Faria muita diferença e importância os pais participando, porque a gente sabe o quanto é cansativo ter uma criança especial. A gente sabe que não é fácil, são crianças que demandam tempo e energia. (E1)

Na percepção dos profissionais, são poucos os pais que se envolvem de maneira efetiva no cuidado do filho. Quando comparecem na instituição para as atividades da criança, preferem permanecer na sala de recepção aguardando o término do atendimento. Os profissionais desconhecem os motivos pelos quais os pais não estão presentes com mais frequência na instituição. Esse fato dificulta a formação de vínculo entre eles. Porém, existem alguns pais que participam mais ativamente do cuidado ao filho e que se mostram dispostos a aprender e a buscar conhecimentos para melhor cuidar da criança.

São poucos os pais que assumem mesmo aquele cuidado, só alguns pais, que são presentes. Eu tenho pacientes que eu nunca vi a mãe, só vejo o pai, mas são poucos. (E4)

Tem pai que nem entra na terapia, entendeu? Fica ali na salinha na frente esperando, daí acaba entrando só a mãe ou a avó. Não sei se é porque não quer, ou se é por outro motivo. (E9)

Eu acho que quando eles têm interesse, eles vão muito bem. Eles têm até aquela preocupação de fazer melhor que a mãe aquele cuidado, é bem interessante! Eles procuram saber para cuidar [...]. (E5)

\subsection{A configuração familiar como referência para o envolvimento do pai no cuidado}

A presença do pai nos atendimentos à criança na instituição é ainda menos frequente quando o pai se separa da mãe e, consequentemente, se afasta da família e dos cuidados do filho. Essa situação reforça o papel da mãe como cuidadora principal e, em muitos casos, ela é a única provedora da casa.

A maioria das nossas famílias, às vezes, nem têm mais a presença do pai, eles se separam mesmo delas, então elas que trazem. (E5) 
A maioria dos pais são separados, são poucos assim que têm a família estruturada né? Daí no geral é a mãe que assume esse papel de cuidador e as crianças são bem apegadas às mães. (E3)

Entretanto, há famílias em que, com a ausência do pai no convívio e cuidados cotidianos, esse papel é assumido, geralmente, pelo avô materno.

Avô é muito presente, eles contam, falam muito do avô. Então o avô é mais próximo daqueles que principalmente não convivem com o pai. (E4)

Acontece bastante de o avô assumir esse papel, principalmente quando a criança ou adolescente que não mora com pai ou não tem contato com o pai, daí ele acaba assumindo esse papel, então acho que seria mais o avô mesmo. (E3)

Quando os pais são ausentes do contexto familiar e/ou do cuidado das crianças, os profissionais percebem frustração e sofrimento por parte das mães, por não poderem contar ou dividir as demandas oriundas da condição do filho com os seus parceiros. Esse contexto leva os profissionais a terem receio de inserir o pai no cuidado da criança e ele não corresponder às expectativas de forma positiva, aumentando a frustração da mãe e a piora dos conflitos no relacionamento familiar.

Muitas mães trazem a frustração pelo pai não estar presente, então eu fico meio preocupada em tentar trazer muito, $e$ esse pai não vir e aumentar a frustração, aí depois vou ter que tentar trabalhar com isso, então acho que, assim, de verdade, acho que elas já têm muita frustração, aí eu acabo não trabalhando muito com a questão do pai não. (E7)

Então você repara que é uma mãe que sofre, não por isso, sofre porque não tem ninguém que possa ajudá-la. Embora, é claro, que tem umas mulheres aqui que não dependem dos seus maridos. (E8)

Os profissionais conseguem compreender melhor a presença e a participação dos pais pela fala das mães ou das crianças durante os atendimentos na instituição. Mesmo quando o pai não é presente nos atendimentos à criança, a figura dele faz parte do cotidiano das interações familiares.

A gente consegue, mesmo que seja verbalmente, na fala delas, saber da rotina, do cuidado que existe essa figura né. (E6)

A gente identifica com as mães que ainda estão junto com os pais na constituição da família a gente identifica: Olha, eu tenho meu marido, ela tem o pai dela, que ajuda. (E5)

\subsection{Os papéis socioculturais das figuras materna e paterna}

Essa categoria discorre sobre a compreensão cultural que os profissionais da equipe de saúde possuem sobre o papel das figuras materna e paterna no cuidado do filho com deficiência, sendo a mãe a referência de cuidado, e o pai o provedor e a autoridade.

Para os profissionais, frequentemente a mãe é a pessoa que se dedica mais ao cuidado do filho com deficiência. Para tanto, ela abdica do trabalho e de projetos pessoais. Esse papel, assumido pela mãe, a faz ser uma referência para os profissionais de saúde, especialmente quando se trata da saúde da criança, e por eles entenderem que, normalmente, as mães são mais afetivas do que o pai e por saberem o que é melhor para o filho. 
A mãe assume totalmente a criança em todas as partes, tanto no tratamento como no acompanhamento escolar e no cuidado em casa. (E4)

É a mãe que é a referência pra tudo. (E4)

Geralmente é a mãe também que se abdica do trabalho para cuidar do filho, pra atender 24 horas o filho. (E3)

No meu entender tem a parte afetiva que geralmente a mulher é mais doada, o homem é um pouco mais sério. (E6)

A figura materna é reconhecida como um indivíduo sobrecarregado em função das demandas com a criança. Os profissionais percebem cansaço, ansiedade e alteração de humor.

Elas entram nesse "eи vou cuidar, eu vou fazer, o que der o meu marido faz, o que não der eu vou suprir”, isso pra mim fica muito claro. (E7)

Por mais que ela tente, o olhar dela, o cansaço começa a se sobressair. (E8)

Eu acho que a mãe já fica mais à flor da pele, já fica mais nervosa, já fica mais ansiosa e às vezes não tem com quem dividir. (E3)

Os profissionais entendem que cabe à figura paterna a função de garantir o sustento da família, ou seja, de ser dela o provedor. Para eles, o pai tem o papel de impor respeito e regras ao filho. Entendem, também, que ele deveria acompanhar a criança e a esposa às atividades de reabilitação.

Pensando na questão psicológica, o pai é a lei né, ele tem que tá lá pra isso. (E7)

Para mim é de cuidar, trazendo a esposa e o filho aqui pra terapia e de trabalhar. (E9)

Então para mim a presença masculina é justamente essa: de pôr regras, de pôr limites, então esse é o papel do pai. (E8)

Os entrevistados também percebem que os próprios pais das crianças e adolescentes com deficiência apresentam o mesmo entendimento sobre o papel da figura paterna, de ser o provedor de sua família, dessa forma acreditando que já cumprem o seu papel.

O homem ainda tem aquela idéia assim: eu estou pagando o médico, então eu estou fazendo a minha parte, eu to levando, to deixando na escola, então eu já to fazendo a minha parte. (E6)

Sempre a mãe ensina: o papai saiu pra trabalhar, porque ele tem que ganhar dinheiro pra sustentar a gente, enquanto isso a mamãe leva você para as terapias. (E8)

\subsection{A figura paterna como referência no cuidado da criança com deficiência}

Os profissionais de saúde identificam diferenças na dinâmica familiar e na evolução da criança quando os pais participam dos seus cuidados, e lançam mão de certos recursos para estimular ainda mais a participação da figura paterna, de maneira efetiva, nos cuidados do filho. 
Na percepção dos profissionais, quando os pais assumem seu papel nos cuidados da criança com deficiência, demonstram conseguir lidar melhor com as dificuldades do cotidiano da família do que as mães, por serem mais racionais e práticos.

Principalmente quando é o pai mesmo que assume. A agilidade da dinâmica daquela família é mais nítida. (E9)

Porque às vezes a mãe não dá conta, e aí acaba indo para o pai e o pai consegue lidar melhor com a situação, acho que talvez venha a questão do homem e da mulher, não sei. O homem é mais racional, a grande maioria, acaba sendo mais racional e aí consegue lidar melhor, segurar melhor, dar conta melhor das dificuldades ali do dia a dia. (E3)

Os entrevistados identificam diferença no comportamento da criança e do adolescente quando o pai é presente. Na percepção deles, as crianças são mais calmas, centradas e se sentem mais seguras para o tratamento de reabilitação. Também identificam que a evolução clínica é melhorada com a participação efetiva da figura paterna nos cuidados e observam que a figura masculina proporciona equilíbrio para a mulher com melhoria da sua autoestima.

A força que a presença do pai ou a figura paterna tem sobre o filho faz com que a criança seja mais centrada. Junto com a figura paterna fica mais calmo e seguro. (E6)

Com esse pai o negócio vai deslanchar muito bem, a criança tem mais essa questão de respeito, minhas melhores evoluções com pacientes são com a figura paterna. (E8)

Eu acho que o pai é um suporte, é um apoio mesmo, é aquele algo a mais, de quando a gente está fragilizado de vir aquela figura masculina e falar pelo menos eu to aqui né, vou te ajudar naquilo que você precisar. (E5)

A figura paterna é fundamental, acho que nesse sentido, de passar mais tranquilidade para as pessoas, mais segurança, mais... deixar mais leve. (E3)

Os profissionais utilizam a conversa e a orientação com os pais presentes e que participam no cuidado do filho na instituição como um recurso para elucidar a sua importância e estimulá-los a serem participantes.

Então como é minoria né, a única coisa que eu faço é conversar mesmo. (E9)

Orientação, a gente chama pra conversar e orienta. Orienta sobre a importância. (E3)

\section{Discussão}

Os resultados deste estudo apontam que os profissionais possuem preparo insuficiente para lidar com a figura paterna, embora reconheçam sua importância. O pai é comumente colocado como coadjuvante no cuidado do filho desde o seu nascimento, proporcionando sobrecarga sobre a figura materna. Tal lacuna é identificada, de acordo com Marcon, Dias, Neves, Marcheti e Lima (2020) no currículo dos profissionais de saúde, destacando a necessidade de se explorar, nos conteúdos de aprendizado, assuntos relacionados às interações familiares, na perspectiva de qualificar a formação e a assistência.

Embora o pai tenha papel fundamental no projeto de vida familiar, ele ainda permanece como uma figura que se destaca pouco, especialmente relativo ao cuidado com a criança. Há a necessidade de os profissionais de saúde estimularem a participação dos pais nos cuidados de seus filhos, utilizando estratégias que chamem a atenção para o seu papel durante o 
atendimento às crianças, fazendo-os reconhecerem como figuras importantes no compartilhamento dos cuidados (Azevedo et al., 2019).

Há de se considerar que entraves advindos de uma cultura tradicional e patriarcal de paternidade podem afetar a atuação paterna no cuidado durante a gestação e em momentos seguintes (Cortez et al., 2016). Assim, a compreensão sociocultural sobre a representação da figura paterna irá conduzir os modos de pensar e agir dos profissionais de saúde baseando-se em representações pré-estabelecidas a respeito de ser pai.

Os profissionais deste estudo relatam que a figura paterna participa pouco do cuidado do filho e, na maioria das vezes, são ausentes na instituição. Por outro lado, destaca-se, cada vez mais, que uma parcela significativa de pais não ocupa apenas o lugar de provedor, mas assume o papel de cuidador e educador (Andrade et al., 2018). Diante das modificações que a sociedade vivencia, é preciso que o profissional esteja preparado para a inserção do pai nas atividades de cuidados, ressignifique sua posição, consequentemente favorecendo o exercício da paternidade.

Os benefícios do pai presente na vida da criança vão além da prática cotidiana. Um estudo que buscou compreender as representações do pai frente ao cuidado com o filho prematuro hospitalizado evidencia que a participação paterna no momento da realização dos cuidados é decisiva, e é a partir da sua inserção na rotina de cuidados do filho que ele se torna empoderado de seu papel. O pai percebe que sua presença é necessária e importante para a recuperação da criança. Essa situação faz com que se sintam aptos a realizar os cuidados necessários ao recém-nascido tanto presentes na unidade como após a alta hospitalar (Borges et al., 2018). Esse processo de compreensão se dá por meio das interações sociais em determinado tempo, espaço e cultura, depois que o estranho se torna familiar e passa a ser um conhecimento aplicável à realidade particular (Moscovici \& Markoval, 1998).

Os participantes deste estudo consideram que, quando os pais são ausentes na vida do filho, a inclusão deles no processo de cuidado é ainda mais difícil. Uma relação conjugal harmoniosa possibilita maior interação entre os membros e a garantia das necessidades dos filhos com deficiência, o que proporciona melhor vínculo e aumento da qualidade de vida (Azevedo et al., 2019). Os pais da atualidade estão em processo de transformação, buscando se aproximar dos filhos, para que as relações sejam mais afetivas e significativas (Mazzo \& Almeida, 2020).

Compreender as experiências vivenciadas pelo pai no cuidado ao filho se faz necessário para que haja melhor manejo e reajuste dos papéis na família, com destaque para a importância da sua inclusão no processo de cuidado. Os profissionais de saúde devem escutar atentamente as demandas da família e compreender sua organização, crenças, papeis e desenvolvimento para a proposição de intervenções que ajudem todos na reorganização do funcionamento familiar e no manejo do cuidado à criança (Marcheti \& Mandetta, 2016).

Como as representações sociais são constituídas no cotidiano, compartilhadas e passam a fazer parte da vida das pessoas, fica claro que é na interação social que os sujeitos elaboram o conhecimento, vão reconstruindo valores e idéias que, compartilhadas, passam a circular na sociedade de modo amplo (Spink, 1993). Evidencia-se, assim, a necessidade de comunicação tanto no espaço de formação quanto no contexto de abrangência familiar para que a informação seja compreendida, ancorada e passe a fazer parte do cotidiano.

Os profissionais percebem que as mães sofrem e se frustram pelo pai não compartilhar os cuidados do filho. Isso reforça que o cotidiano do cuidador de uma criança com deficiência é estressante e que a rede de apoio é de extrema importância. Fica evidente, dessa forma, que a figura paterna é mencionada como uma assistência fundamental de apoio emocional e de cuidado (Christmann et al., 2017).

O modelo tradicional sobre o qual se sustenta o papel da figura paterna para a sociedade apenas como provedor encontra-se em decadência. Afinal, a família é dinâmica e passa por constantes reestruturações em seu âmbito (Branco \& Ciantelli, 2017), e nela o papel do pai é exercido de forma a contribuir no desenvolvimento de seus filhos, favorecendo os 
aspectos afetivos e auxiliando nos cuidados. Reside aí a necessidade, ao se buscar compreender as representações dessas figuras parentais e profissionais, de se ter claro o que bem sintetiza Arruda (2002) sobre o pensamento de Jodelet, exposto a seguir. Para captar as representações sociais é necessário indagar: a) quem sabe e de onde sabe? B) o que sabe e como sabe? C) sobre o que sabe e com que efeito?

Respostas indicativas das percepções tanto de profissionais como de familiares requerem a compreensão do contexto social e cultural de formação dessas pessoas; as reflexões sobre esse pertencimento possibilitam as modificações individuais que, quando socializadas eficazmente, têm o potencial de se transformarem em conhecimento prático. A reconstrução de valores se dá no processo de interação social, pessoa a pessoa, em determinado tempo, espaço e cultura e, a partir dessas informações compartilhadas, o estranho paulatinamente torna-se familiar e os sujeitos vivenciam a realidade (Spink, 1993).

Apesar de a mulher compor, ainda hoje, a principal cuidadora, há homens que se esforçam para participar do desenvolvimento dos filhos, envolvendo-se no cuidado direcionado às crianças. A nova aquisição de papéis é chamada "paternidade participativa", que se caracteriza pelo envolvimento no dia-a-dia dos filhos, em atividades de educação, lazer, alimentação e higiene, e proporciona ao homem o aprender a ser pai, exercendo seu papel de forma exitosa, compreendendo a diversidade da figura paterna, uma vez que, hoje, existem diferentes formas de se exercer esse papel (Visentin \& Lhullier, 2019).

Quando o pai é presente nos cuidados do filho com deficiência, ele proporciona às crianças e adolescentes maior segurança, tranquilidade, confiança e respeito. Os profissionais deste estudo recorrem a diálogos e orientações aos pais para aproximá-los das atividades e participação dos cuidados à criança. Tal conduta é recomendada no âmbito interdisciplinar, visto que os profissionais devem estimular o engajamento dos pais no cuidado de seus filhos por meio da elaboração de estratégias nos serviços, como: orientações, atividades direcionadas a eles, reuniões, grupos ou eventos educacionais (Cruz et al., 2019).

Os profissionais de saúde necessitam compreender a dinâmica familiar e suas relações para proporcionar melhor prática assistencial no cuidado à criança com deficiência e sua família (Marcheti \& Mandetta, 2016). A atuação dos profissionais de saúde com as famílias de crianças com deficiência precisa contribuir para a inclusão do pai no processo do cuidado do filho desde o seu nascimento e em todos os cenários de cuidado.

\subsection{Limitações do estudo}

Destaca-se como fator limitante do estudo o fato de ter sido realizado em uma única instituição de reabilitação que atende crianças com deficiência. Desse modo, os resultados representam apenas uma parcela dessa população.

\subsection{Contribuições para a área da saúde}

Este estudo evidencia a necessidade de proporcionar espaços de discussão interprofissional de modo a buscar estratégias eficazes de inclusão do pai nos atendimentos à criança com deficiência, além de destacar a importância da inclusão da temática e das abordagens que considerem o pai e o sistema familiar no processo de formação profissional.

\section{Conclusão}

Este estudo destacou os elementos determinantes para a inclusão do pai no cuidado do filho com deficiência sob a perspectiva dos profissionais de saúde de instituição de reabilitação. Os profissionais reconhecem a importância da figura paterna no cuidado da criança, mas enfrentam dificuldades em abordar e incluir os pais devido às lacunas em seu processo formativo relativas a conteúdos, abordagens e referenciais sobre família. 
A configuração familiar centrada em papéis socialmente estruturados na sociedade fornece uma referência para o envolvimento ou não envolvimento dos pais no cuidado. As repercussões da ausência ou pouca participação deles na dinâmica familiar provocam sobrecarga emocional e física na figura materna, por vezes ocasionando conflitos familiares.

Os papéis sociais masculinos e femininos ainda vigentes validam a participação da figura paterna como provedor, o que justifica sua ausência no cuidado direto à criança, cabendo à figura materna a responsabilidade pelo cuidado da casa e da família. Destaca-se que há diferença qualitativa no cuidado quando se verifica a presença da figura paterna, visto que propicia à criança segurança e, consequentemente, melhor evolução no tratamento.

Embora a realidade seja de poucos pais participantes no cuidado do filho com deficiência, é preciso que haja a compreensão por parte dos profissionais de saúde de que eles existem, são fundamentais e requerem escuta qualificada, objetivando maior envolvimento deles no processo terapêutico.

Os resultados deste estudo apontam para a necessidade de se desenvolver novas investigações que contemplem outros contextos de cuidados a crianças com deficiência e suas famílias, cuja publicação possa possibilitar a apropriação de novos conhecimentos adaptáveis às demandas do cuidado dessas crianças.

\section{Referências}

Andrade, C. J., Praun, L. D. \& Benincasa, M. (2018). O cuidado dos filhos sob a responsabilidade paterna: mudanças de paradigma nas relações familiares. Vínculo, 15(2), 31-41. https://dx.doi.org/3c79c4f3165443f374c-335b

Arruda, A. (2002). Teoria das representações sociais e teorias de gênero. Caderno de Pesquisa, (117), 127-147. https://doi.org/10.1590/S010015742002000300007

Azevedo, T. L., Cia, F. \& Cássia, C. S. (2019). Correlação entre o relacionamento conjugal, rotina familiar, suporte social necessidades e qualidade de vida de pais e mães de crianças com deficiência. Revista Brasileira de Educação Especial, 25(2), 205-18. https://doi.org/10.1590/s1413-65382519000200002

Bernardi, D. (2017). Paternidade e cuidado: "novos conceitos", velhos discursos. Psicologia Revista, 26(1), 59-80. https://doi.org/10.23925/25943871.2017v26i1p.59-80

Borges, K. I., Oliveira, J. S., Souza, D. A., Silva, V. C. E., Fonseca, K. R. T. P. \& Zani, A. V. (2018). Vivências do pai/homem no cuidado ao filho prematuro hospitalizado. Revista Mineira de Enfermagem, 22(e-1141). Recuperado de http://www.reme.org.br/exportar-pdf/1280/e1141.pdf. doi: 10.5935/14152762.20180071

Branco, A. P. S. C. \& Ciantelli A. P. C. (2017). Interações familiares e deficiência intelectual: uma revisão de literatura. Pensando famílias, 21(2), 149-66. Recuperado em 01 de dezembro de 2021, de http://pepsic.bvsalud.org/scielo.php?script=sci_arttext\&pid=S1679-494X2017000200012\&lng=pt\&tlng=pt.

Brasil (2015). Lei n. 13.146, de 6 de julho de 2015. Institui a Lei Brasileira de Inclusão da Pessoa com Deficiência (Estatuto da Pessoa com Deficiência). Diário Oficial da União, Brasília. Recuperado em 06 de novembro de 2021, de http://www.planalto.gov.br/ccivil_03/_ato2015-2018/2015/lei/113146.htm

Braun, V. \& Clarke, V. (2019). To saturate or not to saturate? Questioning data saturation as a useful concept for thematic analysis and sample-size rationales. Qualitative Research in Sport, Exercise and Health, 13(2), 201-216. https://doi.org/10.1080/2159676X.2019.1704846

Christmann, M., De Andrade, M. A. S., Da Rocha, M. .M. \& Carreiro, L. R. R. (2017). Estresse materno e necessidade de cuidado dos filhos com TEA na perspectiva das mães. Cadernos de Pós-Graduação em Distúrbios do Desenvolvimento, 17(2), 8-17. https://dx.doi.org/10.5935/cadernosdisturbios.v17n2p8-17

Cortez, M. B., Machado, N. M., Trindade, Z. A. \& Souza, L. G. S. (2016). Profissionais de saúde e o (não) atendimento ao homem-pai: análise em representações sociais. Psicologia em estudo, 21(1), 53-63. https://doi.org/10.4025/psicolestud.v21i1.28323

Cruz, T. A. R., Santos, E. M. S., Silva, F. C., Silva, M. C. R. \& Silva, A. C. D. (2019). Perfil sociodemográfico e participação paterna nos cuidados diários de crianças com microcefalia. Cadernos Brasileiros de Terapia Ocupacional, 27(3), 602-614. https://doi.org/10.4322/2526-8910.ctoAO1830

Félix, V. P. S. R. \& Farias, A. M. (2018). Microcefalia e dinâmica família: a percepção do pai frente à deficiência do filho. Caderno de Saúde Pública, 34(12). https://doi.org/10.1590/0102-311X00220316

Marcheti, M. A. \& Mandetta, M. A. (2016). Cartas terapêuticas: uma intervenção eficaz com famílias de crianças com deficiência. Revista Pesquisa Qualitativa, 4(6), 408-422. Recuperado em 01 de dezembro de 2021, de https://editora.sepq.org.br/rpq/article/view/64/49

Marcheti, M. A. \& Mandetta, M. A. (2016). Intervenção com família de criança com deficiência fundamentada em um marco teórico desenvolvido com base no modelo de vulnerabilidade e resiliência. Debates, 6(4) 58-79. https://doi.org/10.36524/dect.v6i04.179

Marcon, S.S., Dias, B. C., Neves, E. T., Marchetti, M. A. \& Lima, R. A. G. (2020). (In)visibilidade de crianças com necessidades especiais de saúde e suas famílias na atenção primária. Revista Brasileira de Enfermagem, 73(Suppl 4). https://doi.org/10.1590/0034-7167-2019-0071

Mazzo, C. M. F. \& Almeida, J. M. T. (2020). O significado de ser pai na atualidade: um estudo na abordagem gestáltica. Revista da Abordagem Gestáltica, 26(1), 26-37. https://dx.doi.org/10.18065/RAG.2020v26n1.3 
Research, Society and Development, v. 10, n. 16, e389101623647, 2021

(CC BY 4.0) | ISSN 2525-3409 | DOI: http://dx.doi.org/10.33448/rsd-v10i16.23647

Minayo, M. C. S. (2010). Ciência, Técnica e Arte: O desafio da pesquisa social. In: Minayo, M. C. S. (Org.); Deslandes, S. F. \& GOMES, R. Pesquisa social. Teoria, método e criatividade (21a ed., pp. 9-15). Vozes.

Minayo, M. C. S. (2014). O desafio do conhecimento: pesquisa qualitativa em saúde. (1a Ed., pp. 416). Hucitec.

Morse, J. M. (2008). Styles of collaboration in qualitative inquiry. Qualitative Health Research, 18(1), 3-4. https://doi.org/10.1177\%2F1049732307309451

Moscovici, S. \& Markova, I. (1998). Presenting social representations: a conversation. Culture \& Society, 4(3), 371-410. https://doi.org/10.1177\%2F1354067X9800400305

Reis, K. M. N., Alves, G. V., Barbosa, T. A., Lomba, G. O. \& Braga, P. P (2017). A vivência da família no cuidado domiciliar à criança com necessidades especiais de saúde. Ciência y enfermeria, 23(1), 45-55. http://dx.doi.org/10.4067/S0717-95532017000100045

Spink, M. J. P. (1993). O conceito de representação social na abordagem psicossocial. Caderno Saúde Pública, 9(3), 300-308. https://doi.org/10.1590/S0102$311 \mathrm{X} 1993000300017$

Tong, A., Sainsbury, P. \& Craig, J. (2007). Consolidated criteria for reporting qualitative research (COREQ): a 32-item checklist for interviews and focus groups. International Journal for Quality in Health Care, 19(6), 349-357. https://doi.org/10.1093/intqhe/mzm042

Visentin, P. M. \& Lhullier, C. (2019). Representações sociais da paternidade: um estudo comparativo. Revista de Psicologia, 31(3), 305-312. https://doi.org/10.22409/1984-0292/v31i3/5640

Vitiritti, B., Marcheti, M. A. \& Giuliani, L. R. (2015). Percepções paternas quanto às suas expectativas sobre o futuro do filho com deficiência mental. Ciência, cuidado e saúde, 14(3), 1346-1353. https://doi.org/10.4025/cienccuidsaude.v14i3.25640 